Journal of Agrometeorology 23 (2) : 207-212 (June 2021)

\title{
Modeling of aphid complex and its associated natural enemies in rapeseed-mustard in relation to climatic factors
}

\author{
SAURBH SONI*, SURJEET KUMAR, AJAY KUMAR SOOD and RANBIR SINGH RANA ${ }^{1}$ \\ Dept. of Entomology, ${ }^{1}$ Centre for Geo-Informatics Research and Training \\ CSK Himachal Pradesh Krishi Vishvavidyalaya Palampur, India \\ *Corresponding author: saurbhsoni@gmail.com
}

\begin{abstract}
Effect of climatic factors on population build-up of aphid complex of rapeseed-mustard viz. mustard aphid, Lipaphis erysimi (Kaltenbach), cabbage aphid, Brevicoryne brassicae (Linnaeus), and green peach aphid, Myzus persicae (Sulzer) and associated natural enemies (coccinellids, syrphids and a parasitoid, Diaeretiella rapae M'Intosh) was studied at Experimental Farm of CSK HPKV Palampur over a period of three years. Correlation coefficients indicated that the temperature favoured build-up of aphid population and their natural enemies while rainfall exerted negative impact. The population of coccinellids was negatively correlated with the population of $L$. erysimi and M. persicae while, positive correlation with B. brassicae was observed. On the other hand, population of syrphids was found to be positively correlated with aphid population. Predictive model using stepup regression analysis revealed that a weak relation in aphid population was attributed by weather parameters particularly minimum, maximum temperature and bright sunshine hours. Regression analysis revealed that 89 per cent variation in parasitization by $D$. rapae was attributed by minimum and maximum temperature, rainfall, relative humidity and bright sunshine hours.
\end{abstract}

Key words: Lipaphis erysimi, Brevicoryne brassicae, Myzus persicae, correlation, regression

The rapeseed-mustard group broadly includes, Indian mustard (Brassica juncea L. Czernj. \& Cosson), toria (B. rapa var. toria), yellow sarson (B. rapa var. yellow sarson), brown sarson (B. rapa var. brown sarson) and gobhi sarson (B. napus L.). Bakhetia and Sekhon (1989) documented about 40 insect-pests harboured on the rapeseed-mustard, where about half a dozen are serious threats to cultivation of these crops. Among various insects, aphid complex comprising mustard aphid, Lipaphis erysimi (Kaltenbach), cabbage aphid, Brevicoryne brassicae (Linnaeus), and green peach aphid, Myzus persicae (Sulzer) are serious pests and one of the important limiting factors in the production of rapeseedmustard. Climatic factors like temperature, relative humidity, sunshine hours and rainfall play vital role in multiplication and distribution of insect-pests. Predictive model for pest forecast is an important tool for effective integrated pest management strategy. Therefore, a good understanding of pest population dynamics is of vital importance for crop protection. Climatic factors play an important role on the aphid appearance, multiplication and disappearance (Vekaria and Patel, 2000). Keeping in view the importance of the crop and the damage caused by these species of aphids, the present investigations were initiated to study the population build- up of aphid complex i.e. L. erysimi, B. brassicae and $M$. persicae on rapeseed-mustard, and the population dynamics of associated natural enemies (Coccinellids, syrphids and a parasitoid, Diaeretiella rapae McIntosh) in relation to climatic factors under natural field conditions.

\section{MATERIALS AND METHODS}

The present investigation was conducted during 2015-16 to 2017-18 in the Experimental Farm of the Department of Entomology, CSK HPKV Palampur, Himachal Pradesh, India $\left(32.1003^{\circ} \mathrm{N}\right.$ latitudes, $76.5465^{\circ} \mathrm{E}$ longitudes $)$.

For this purpose, mustard variety RCC-4 was raised in the experimental farm of the Department of Entomology following recommended package of practices during rabi 2015-16, 2016-17 and 2017-18. Data were recorded on the population of different aphid species and their natural enemies (NE's) following standard sampling methodology. Observations were recorded in the following manner:

Aphids

The population of aphids at initial stage mostly remains low and thus count was made on leaves and shoots as well. After the stem elongation, terminal $10 \mathrm{~cm}$ of the main 
shoot formed the sampling unit. Samples were randomly collected from 150 plants at weekly intervals from the time of appearance of the aphids till the harvest of the crop and counts were made separately for L. erysimi, B. brassicae and M. persicae by using the method of Mathur and Singh, (1986).

\section{Predators}

Observations on the population of coccinellids (total number of adults and grubs/plant) and syrphids (total number of maggots $/ 10 \mathrm{~cm}$ apical twig) were recorded simultaneously while recording population of aphids on randomly selected 50 plants at weekly intervals as per the sampling method used by earlier workers (Lakhanpal, 1994) with some modifications.

\section{Parasitoid}

Parasitization (\%) by D. rapae was worked out by taking direct counts on number of mummified and healthy aphids at the time of recording aphid population as per the formula given by Root and Skelsey (1969):

$$
\text { Per cent parasitization }=\frac{\text { Number of parasitized aphids }}{\text { Total number of aphids (healthy and parasitized) }} \times 100
$$

\section{Statistical analysis}

To study the impact of climatic factors on the population build-up of aphids and their natural enemies, the meteorological data (weekly means) for temperature (minimum and maximum), relative humidity (\%), rainfall (mm) and bright sunshine (hrs) recorded during the observation period were obtained from the Department of Agronomy, CSK HPKV, Palampur. Correlation coefficients were worked out for the population build-up (means of pooled data of three cropping seasons) of three aphid species and their natural enemies in relation to climatic factors. Further, step-wise linear regression model was developed for estimating aphid and their natural enemy population with the climatic parameters namely, temperature (minimum and maximum), relative humidity (\%), rainfall $(\mathrm{mm})$ and bright sunshine hours (hrs).

\section{RESULTS AND DISCUSSION}

\section{Population build-up of aphids and their natural enemies}

The perusal of pooled data (based on three cropping seasons) revealed that among the three aphid species, $L$. erysimi was the first to appear on the crop in the month of December (49 ${ }^{\text {th }}$ SMW) and remained active for a longer duration followed by B. brassicae and M. persicae (Table 1,
Fig. 1). The infestation of M. persicae was noted in the third week of January ( $3^{\text {rd }}$ SMW) and it continued up to the last week of March (12 $2^{\text {th }}$ SMW). B. brassicae appeared on the crop late in last week of January ( $4^{\text {th }}$ SMW) as compared to the other two aphid species but its infestation continued up to the harvesting of the crop in the third week of April $\left(15^{\text {th }}\right.$ SMW). Observations recorded on the NE's associated with the aphids revealed the prevalence of two groups of predatory species viz. coccinellids, syrphids and one parasitoid, Diaeretiella rapae (McIntosh). Among coccinellids, Coccinella septempunctata was the predominant species. Cheilomenes sexmaculata (Fab), Hippodamia variegata (Goeze) and Harmonia dimidiata Fab were also observed but their population was low. Ischiodon scutellaris (Fab) and Episyrphus balteatus (De Geer) were found to be the predominant syrphid species. The pooled data showed that the coccinellids and syrphids started appearing in second and first week of February ( $6^{\text {th }}$ and $5^{\text {th }}$ SMW), respectively. The parasitization by D. rapae was first noted in the second week of January ( $2^{\text {nd }}$ SMW) (Table 1). Our results are in agreement to Mehnaj et al. (2017), who reported the appearance of L. erysimi and its peak activity in $51^{\text {st }} \mathrm{SMW}$ and $8^{\text {th }} \mathrm{SMW}$, respectively. Prasad et al. (2013) reported that B. brassicae, M. persicae and L. erysimi have been observed to be the most important aphids to cause economic damage on oilseed Brassicas although, population of the $B$. brassicae remains always greater than other species.

\section{Effects of abiotic factors on population build-up}

The data revealed that maximum temperature had a significant negative correlation with L. erysimi population ( $\mathrm{r}=$ -0.33) (Table 2). However, a significant positive relationship of $B$. brassicae population was recorded with maximum and minimum temperature $(\mathrm{r}=0.72$ and 0.73$)$, whereas, $\mathrm{RH}$ showed a significant negative correlation $(\mathrm{r}=-0.67)$. The population of $M$. persicae was found to be significantly negatively correlated to rainfall $(\mathrm{r}=-0.56)$, while BSS showed a significant positive correlation $(\mathrm{r}=0.44)$. The correlation coefficients between pooled average population of NE's with pooled means of meteorological parameters were worked out which have been given in table 2. Maximum and minimum temperature showed a significant positive correlation $(\mathrm{r}=0.94$ and 0.94$)$ with population of coccinellids. The correlation coefficients worked out for population of syrphids indicated a significant negative correlation with maximum temperature $(\mathrm{r}=-0.46)$ and a significant positive correlation with $\mathrm{RH}(\mathrm{r}=$ 0.76). Data revealed that pararsitization by $D$. rapae showed 
Table 1: Population build-up of aphids on rapeseed-mustard at Palampur (based on pooled data of 2015-16 to 2017-18)

\begin{tabular}{clcccccc}
\hline \multirow{2}{*}{ SMW } & Dates of & \multicolumn{3}{c}{ Aphid population*¥ } & \multicolumn{2}{c}{ Population of natural enemies $€ £$} \\
\cline { 3 - 7 } & observation & L. erysimi & B. brassicae & M. persicae & Coccinellids & Syrphids & D. rapae \\
\hline 49 & Dec-9 & 0.23 & 0.00 & 0.00 & 0.00 & 0.00 & 0.00 \\
50 & Dec-16 & 0.26 & 0.00 & 0.00 & 0.00 & 0.00 & 0.00 \\
51 & Dec-23 & 1.82 & 0.00 & 0.00 & 0.00 & 0.00 & 0.00 \\
52 & Dec-31 & 3.38 & 0.00 & 0.00 & 0.00 & 0.00 & 0.00 \\
1 & Jan-7 & 8.56 & 0.00 & 0.00 & 0.00 & 0.00 & 0.00 \\
2 & Jan-14 & 12.35 & 0.00 & 0.00 & 0.00 & 0.00 & 0.14 \\
3 & Jan-21 & 15.96 & 0.00 & 0.04 & 0.00 & 0.00 & 2.96 \\
4 & Jan-28 & 17.80 & 0.54 & 0.09 & 0.00 & 0.00 & 2.99 \\
5 & Feb-4 & 21.05 & 2.69 & 0.64 & 0.00 & 0.02 & 6.98 \\
6 & Feb-11 & 19.28 & 3.85 & 1.18 & 0.14 & 0.13 & 13.16 \\
7 & Feb-18 & 18.67 & 8.99 & 1.00 & 0.36 & 0.16 & 25.26 \\
8 & Feb-25 & 13.86 & 14.28 & 0.93 & 0.68 & 0.19 & 32.28 \\
9 & March-4 & 13.14 & 25.88 & 0.76 & 0.94 & 0.19 & 36.53 \\
10 & March-11 & 8.90 & 21.65 & 0.20 & 0.76 & 0.06 & 41.57 \\
11 & March-18 & 9.35 & 20.94 & 0.34 & 1.36 & 0.05 & 48.16 \\
12 & March-25 & 2.87 & 20.42 & 0.15 & 1.69 & 0.03 & 45.46 \\
13 & April-1 & 0.94 & 25.34 & 0.00 & 1.59 & 0.00 & 50.42 \\
14 & April-8 & 0.00 & 19.55 & 0.00 & 1.67 & 0.00 & 26.94 \\
15 & April-15 & 0.00 & 15.49 & 0.00 & 0.95 & 0.00 & 9.55 \\
\hline
\end{tabular}

*Average of 150 observations; SMW - Standard meteorological week; ¥At initial stage of crop growth, counts were made on whole plant, whereas, after stem elongation, terminal $10 \mathrm{~cm}$ of the apical shoot formed the sampling unit.; $€$ Average of 50 observations $£$ Coccinellids $=$ number of adults and grubs per plant; Syrphids $=$ number of larvae per $10 \mathrm{~cm}$ apical twig; D. rapae = per cent parasitization

a significant positive correlation with maximum $(\mathrm{r}=0.83)$ and minimum temperature $(\mathrm{r}=0.86)$, while a significant negative correlation with RH $(r=-0.73)$ was observed. The findings of present investigation are supported by Ali and Rizvi (2012) who observed that population of L. erysimi was negatively correlated with minimum, maximum temperature, rainfall and sunshine hours. In similar study, Kumar and Paul (2017) reported that maximum temperature was negatively correlated with the M. persicae population. On the other hand, Raja et al. (2014) reported a positive correlation between population of $B$. brassicae and maximum, minimum temperature and bright sunshine hours, whereas negative correlation with RH and rainfall. Coccinellids and D. rapae exhibited positive correlation with maximum, minimum temperature and sunshine hours. Our findings are in support with Yadav and Agrawal (2018) who reported that the population of coccinellids was highly affected by maximum and minimum temperature. The sunshine also had a positive correlation with build-up of coccinellids, whereas RH showed a negative correlation. Akhtar et al. (2010) showed that relative humidity had a negative correlation with parasitization by D. rapae, while a positive correlation with temperature was observed. The reason for this negative correlation could possibly be due to the fact that population of natural enemies did not synchronize with respective weather parameters. The study revealed that the temperature and sunshine hours showed negative correlation with syrphid population. Similar observations were also reported by Paul and Konar (2005).

\section{Correlation ( $r$ ) between aphids and their natural enemies}

The perusal of data in table 3 revealed that the population of coccinellids had a significant negative correlation with L. erysimi $(\mathrm{r}=-0.91)$ and $M$. persicae $(\mathrm{r}=$ $0.89)$ population, whereas, significant positive correlation with population of $B$. brassicae $(\mathrm{r}=0.50)$. It is clear from data that the population of coccinellids increased gradually with the increase of aphid population and then resulting in gradual decrease in aphid population. The syrphids had a significant positive correlation with the population of $L$. erysimi.. The data reveal similar results for correlation studies between coccinellids and $M$. persicae, depicting negative correlation as a result of asynchronizaton. However, appearance of coccinellids at later stage of the crop with maximum population of $B$. brassicae was favourable for coccinellid predators. Talpur and Khuhro (2004) also reported that coccinellid beetles appeared at later stage of the crop when 

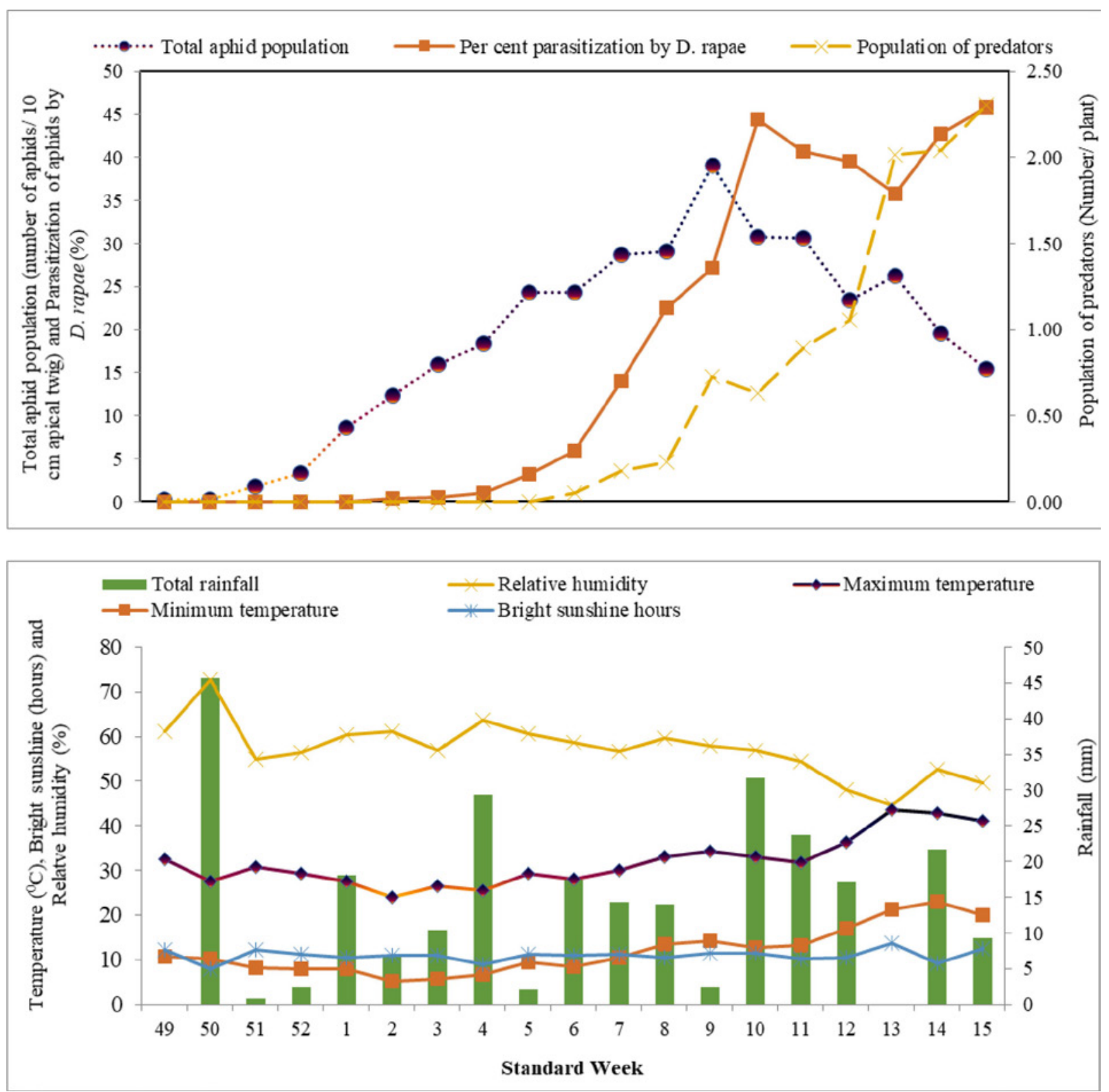

Fig. 1: Population build-up of aphids and their natural enemies (based on the pooled data from 2015-16 to 2017-18) at Palampur

there was maximum population of aphids on the crop. Data presented in table 1 revealed that peak activity of aphids and syrphids fall in the first week of March and then gradually decreased with decrease in aphid population revealing a positive correlation between aphid population and syrphids. This indicated the positive role of syrphids in suppressing the aphid population in the field. In conformity with our findings, Devi et al. (2011) observed similar results. The data on the relationship between aphid population and per cent parasitization revealed that the activity of $D$. rapae was directly influenced by the presence of aphid population in the field. These results are in corroboration with the findings of Nieto et al. (2006) who reported that the presence of mummified aphids was positively correlated to $B$. brassicae infestation at cabbage harvest.

\section{Regression analysis}

Based on the data clubbed for three cropping seasons, it was evident that maximum, minimum temperature and sunshine hours contributed 41 per cent variation in aphid population (Table 4) and was depicted in predictive model. In case of natural enemies, it was evident from data that minimum temperature and relative humidity was found to influence predator population significantly and contributed to the extent of 90 per cent variation. Whereas, in case of parasitization by $D$. rapae, minimum and maximum 
Table 2: Correlation (r) between various abiotic factors and population of aphids and their natural enemies on rapeseed-mustard

\begin{tabular}{|c|c|c|c|c|c|c|c|}
\hline \multirow[b]{2}{*}{ Factor } & \multicolumn{4}{|c|}{ Population of aphids } & \multicolumn{3}{|c|}{ Natural enemies } \\
\hline & $\begin{array}{l}\text { L. erysimi } \\
\qquad(\mathrm{n}=46)\end{array}$ & $\begin{array}{l}\text { B. brassicae } \\
(\mathrm{n}=34)\end{array}$ & $\begin{array}{l}\text { M. persicae } \\
(\mathrm{n}=21)\end{array}$ & $\begin{array}{l}\text { Total aphid } \\
\text { population }\end{array}$ & $\begin{array}{l}\text { Coccinellids } \\
\quad(n=27)\end{array}$ & $\begin{array}{l}\text { Syrphids } \\
(\mathrm{n}=21)\end{array}$ & $\begin{array}{c}\text { Parasitization }(\%) \\
\qquad(n=37)\end{array}$ \\
\hline Maximum temperature & $-0.33^{*}$ & $0.72 *$ & -0.14 & 0.30 & $0.94 *$ & $-0.46^{*}$ & $0.83 *$ \\
\hline Minimum temperature & -0.24 & $0.73 *$ & -0.20 & 0.37 & $0.94^{*}$ & -0.43 & $0.86^{*}$ \\
\hline $\mathrm{RH}$ & 0.01 & $-0.67 *$ & 0.23 & -0.36 & $-0.80^{*}$ & $0.76^{*}$ & $-0.73^{*}$ \\
\hline Bright sunshine hours & -0.03 & 0.41 & $0.44 *$ & 0.12 & 0.31 & -0.43 & 0.26 \\
\hline
\end{tabular}

* Significant at 5\% level

Table 3: Correlation (r) between aphids and their natural enemies on rapeseed-mustard

\begin{tabular}{cccc}
\hline Aphid & $\begin{array}{c}\text { Population } \\
\text { of } \\
\text { coccinellids }\end{array}$ & $\begin{array}{c}\text { Population } \\
\text { of syrphids }\end{array}$ & $\begin{array}{c}\text { Parasitization } \\
\text { by D. rapae } \\
(\%)\end{array}$ \\
\hline L. erysimi & $-0.91^{*}$ & $0.46^{*}$ & - \\
B. brassicae & $0.50^{*}$ & 0.09 & - \\
M. persicae & $-0.89 *$ & 0.11 & - \\
Total aphid & & $0.81 *$ & -0.23 \\
population & $-0.59^{*}$ & & \\
\hline
\end{tabular}

* Significant at 5\% level

temperature, rainfall, relative humidity and sunshine hours were found to be the major contributing factors and the equation obtained by stepwise multiple regression depicted that these factors significantly resulted in 89 per cent variation. It is evident from the stepwise regression equations that climatic factors greatly influenced the population dynamics of aphids and associated natural enemies. Seasonal variations of the weather factors play a vital role in multiplication, growth, development and distribution of insects, and have influence on their population dynamics (Dhaliwal and Arora, 2001). Sahoo (2013) from the stepwise regression analysis observed that the combined influence of rainfall, temperature and $\mathrm{RH}$ resulted in 70, 62 and 41 per cent variation in L. erysimi population during 2009-10, 201011 and 2011-12. Sahoo and Saha (2018) observed the impact of rainfall, temperature, relative humidity and wind speed on incidence of $L$. erysimi through stepwise regression analysis and it was noted that the combined influence of these weather parameters was 54 per cent. Mandal et al. (2018) reported that temperature individually exerted 77.9 per cent effect on
Table 4: Regression model for aphids and their associated natural enemy population build-up on rapeseedmustard

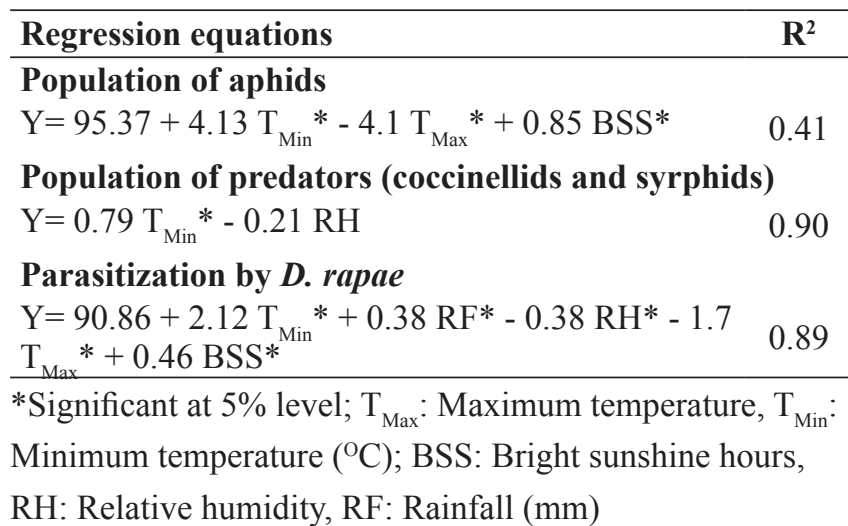

population abundance of aphid in mustard. The temperature with combination of light intensity provided 81.3 per cent abundance. The combined effect of temperature, light intensity and relative humidity depicted 81.7 per cent abundance. The multiple linear regression analysis showed that the three weather parameters together contributed on the abundance of mustard aphid, but the temperature had the greater effect than others.

\section{CONCLUSIONS}

Based on the investigations, it is concluded that three aphid species viz. L. erysimi, B. brassicae and $M$. persicae were found to infest rapeseed-mustard at Palampur. Among climatic factors, temperature exhibited negative correlation with $M$. persicae and L. erysimi population whereas positive relationship with population of $B$. brassicae. Rainfall exerted negative influence on aphid population. Coccinellids and parasitoid, D. rapae showed a strong positive correlation with temperature and sunshine hours whereas, syrphids showed negative correlation with temperature. Parasitization and predation of aphids was also observed to increase with rise in maximum and minimum temperature. 


\section{REFERENCES}

Akhtar, M.S., Dey, D., Usmani, M.K and Choudhury, R.A. (2010). Seasonal abundance of Diaretiella rapae (M'Intosh) (Braconidae: Aphidiinae) parasitizing Lipaphis erysimi (Kaltenbach) (Hemiptera: Aphididae) in Brassica juncea variety Pusa bold. Mun. Ent. Zool., 5: 692-696.

Ali, A. and Rizvi, P.Q. (2012). Influence of abiotic and biotic factors on the population dynamics of mustard aphid, Lipaphis erysimi (Kalt.) on Indian mustard, Brassica juncea with respect to sowing dates. Acad. J. Plant Sci., 5(4):123-127.

Bakhetia, D.R.C. and Sekhon, B.S. (1989). Insect-pests and their management in rapeseed-mustard. J. Oilseeds Res., 6:269-299.

Devi, Y.R., Kalita, J. and Singh, T.K. (2011). Biological control potential of an aphidophagous syrphid, Episyrphus balteatus, De-Geer (Diptera:Syrphidae) on mustard aphid, Lipaphis erysimi (Kalt.) (Homoptera:Aphididae) on cabbage ecosystem in Manipur. J. Exp. Sci., 2(12):13-16.

Dhaliwal, G.S. and Arora, R. (2001). Integrated pest management-concepts and approaches. Kalyani Publishers, New Delhi, India, pp. 27-60.

Kumar, J. and Paul, B. (2017). Population dynamics of aphid, Myzus persicae (Sulzer) (Hemiptera: Aphididae) on different Brassica species. Agric. Sci. Digest., 37(1):64-67.

Lakhanpal, G.C. (1994). Management of aphids on rapeseed with biocontrol agents. $\mathrm{PhD}$ Thesis. Department of Entomology, CSK HP Krishi Vishvavidyalaya, Palampur, India.

Mandal, E., Amin, M.R., Rahman, H. and Akanda, A.M. (2018). Infestation level and population dynamics of aphid on mustard. Bangladesh J. Agric. Res., 43(4):611-618.

Mathur, Y.K. and Singh, S.V. (1986). Population dynamics of Myzus persicae Sulzer and Lipaphis erysimi (Kalt.) on rapeseed and mustard in U.P. J. Oilseeds Res., $3(2): 246-250$.

Mehnaj, T.A., Singh, Y.P., Basant, K.K., Singh, K.K. and Pandey, A.C. (2017). Forewarning model development for mustard aphid (Lipaphis erysimi
Kalt.) at Bharatpur and Hisar. J. Agrometeorol., 19(4): 334-341.

Nieto, D.J., Shennan, C., Settle, W.H., O’Malley, R., Bros, S. and Honda, J.Y. (2006). How natural enemies and cabbage aphid (Brevicoryne brassicae L.) population dynamics affect organic broccoli harvest. Environ. Entomol., 35:94-101.

Paul, S. and Konar A. (2005). Ecological study on the occurrence of chili thrips in plains of West Bengal. Indian J. Ecol., 32:102-103.

Prasad, R., Kumari, V., Sharma, A. and Sehgal, S. (2013). A study on high incidence of mustard aphids, Brevicoryne brassicae and Myzus persicae on Gobhi Sarson during warmer and drier winters at Palampur, Himachal Pradesh. J. Agrometeorol., 15(2): 170-173.

Raja, M., William, J. and David, B.V. (2014). Population dynamics of key insect pests of cabbage in Tamil Nadu. Indian J. Entomol., 76(1):1-7.

Root, R.B. and Skelsey, J.J. (1969). Biotic factors involved in crucifer aphid outbreaks following insecticide application. J. Econ. Entomol.,., 62:223-233.

Sahoo, S.K. (2013). Population dynamics of mustard aphid, Lipaphis erysimi (Kaltenbach) (Hemiptera: Aphididae) on Brassica germplasm. Indian $J$. Entomol., 75(1): 9-14.

Sahoo, S.K. and Saha, A. (2018). Monitoring of alate mustard aphid, Lipaphis erysimi (Kaltenbach) by using yellow sticky trap in West Bengal. J. Crop Weed 14(3): 149-152.

Talpur, M.A. and Khuhro, R.D. (2004). Relative occurrence and abundance of mustard aphid, Lipaphis erysimi (Kalt.) and their predators on rainbow and oscar canola varieties. J. Asia Pac. Entomol. 7(2):215-219.

Vekaria, M.V. and Patel, G.M. (2000). Screening of promising Brassica and allied genotypes for resistance against mustard aphid, Lipaphis erysimi Kalt. (Homoptera: Aphididae). Applied Biol. Res., 4(1-2):75-77.

Yadav, N. and Agrawal, N. (2018). Seasonal abundance of brevicoryne brassicae L. and their predators under different field of cabbage in relation to weather parameters. J. Entomol. Zool. Stud., 6(5):1098-1101. 